\title{
Uji Performansi Instrument Berbasis Teknologi Laser Photo-Accoustics Untuk
} Deferensiasi Kopi

\author{
(Performance test instrument based on laser photo acoustic technology for coffee \\ differentiation)
}

\author{
Giar Pramanda Putra ${ }^{1}$, Ratna $^{1}$, Agus Arip Munawar ${ }^{\text {* }}$ \\ ${ }^{1}$ Program Studi Teknik Pertanian, Fakultas Pertanian, Universitas Syiah Kuala \\ *Corresponding author: aamunawar@unsyiah.ac.id
}

\begin{abstract}
Abstrak. Penelitian ini bertujuan untuk memanfaatkan instrument berbasis teknologi Laser Photo Acoustics untuk membedakan biji kopi berdasarkan perbedaan daerah dan jenis kopi. Penelitian ini menggunakan softwere The Unscrambler X 10.5 Parameter penelitian meliputi penggunaan metode PCA (partial component analysis) dengan mengguanakan pretreatment baseline correction dan klasifikasi biji kopi beserta perbedaan daerah penghasil kopi dengan total 40 sampel tembakan laser antara lain 20 sampel biji kopi arabika dan 20 sampel biji kopi robusta. Hasil penelitian menunjukkan bahwa uji performansi alat laser photo acoustics ini mampu mendeteksi perbedaan kopi berdasarkan klasifikasi daerah penghasil kopi antara biji kopi daerah bener meriah dan biji kopi daerah takengon, kemudian dengan melihar perbandingan perbedaan dengan klasifikasi biji kopi berdasarkan jenis kopi arabika dan robusta belum bias terdeteksi dengan alat ini dikarenakan beberapa factor salah satunya ialah sensor pembaca gelombang dari alat ini masih kurang peka terhadap deferensiasi jenis kopi robusta dan arabika.
\end{abstract}

Kata kunci : Kopi, Jenis kopi, Alat Laser photo acoustics.

\begin{abstract}
This study aims to utilize an instrument based on Laser Photo Acoustics technology to distinguish coffee beans based on different regions and types of coffee. This study uses the software The Unscrambler X 10.5 Research parameters include the use of the PCA method using pretreatment baseline correction and coffee bean classification along with differences in coffee producing regions with a total of 40 laser shot samples including 20 samples of arabica coffee beans and 20 samples of robusta coffee beans. The results showed that the performance test of the photo acoustics laser tool was able to detect differences in coffee based on the classification of coffeeproducing regions between coffee beans and the coffee beans in the takengon area, then by comparing the differences with the classification of coffee beans based on Arabica and robusta coffee types could not be detected with this tool due to several factors, one of which is the wave reader sensor from this device is still less sensitive to the differentiation of robusta and arabica coffee types.
\end{abstract}

Keywords: Coffee, Type Coffee, A Laser photo acoustics. 


\section{PENDAHULUAN}

Kopi adalah sejenis minuman yang berasal dari proses pengolahan dan ekstraksi biji tanaman kopi. Secara umum terdapat dua jenis biji kopi, yaitu kopi arabika (Coffea Arabica dan kopi robusta (Coffea canephora) (Edy panggabean, 2011). Kopi merupakan salah satu minuman yang tersebar luas dan termasuk minuman yang mayoritas banyak diminum di dunia (Sofyana Nadya, 2011). Kopi mengandung senyawa antioksidan dapat membantu tubuh dalam menangkal efek perusakan oleh senyawa radikal bebas dalam tubuh dan memperbaiki sel sel yang rusak. Kopi dapat membantu kita agar tetap terjaga dan fokus (Edy, 2011). Tantangan teknologi masa kini dimana diperlukan teknologi yang cepat, tepat dan akurat. Laser PhotoAccoustics merupakan salah satu alternative untuk menjawab tantangan zaman. Pada penelitian ini akan dicoba uji performansi alat Laser Photo-Accoustics untuk diferensiasi biji kopi Arabica dan robusta.

\section{METODE PENELITIAN}

\section{Tempat dan Waktu}

Penelitian ini akan dilaksanakan pada bulan Februari sampai dengan Maret 2018, bertempat di Laboratorium Instrumentasi dan Energi Program Studi Teknik Pertanian Fakultas Pertanian Universitas Syiah Kuala, Kota Banda Aceh.

\section{Alat dan Bahan}

Peralatan yang akan digunakan dalam penelitian ini adalah Laser Photo-Accoustics serta unscrambler software ${ }^{\circledR} X$ version 10.5 . Bahan yang akan digunakan adalah 2 jenis biji kopi Arabika dan 2 jenis biji kopi Robusta dari kota Takengon dan Kabupaten Bener Meriah, Jumlah sempel keseluruhan adalah 4 sampel dengan masing-masing sampel mendapatkan 10 kali penembakan dan total penembakan laser 40 kali.

\section{Prosedur Penelitian}

Proses awal dari penelitian ini setelah kopi diklasifikasi berdasarkan perbedaan jenis dan perbedaan daerah kemudian kopi tersebut ditembakkan laser dengan durasi 5 detik persampel sampai dengan 40 sampel lalu data yang didapat menjadi format data excel yang dilihat dengan menggunakan software The Unscrambler X 10.5 untuk menggunakan metode PCA dan di pretreatment dengan baseline correction lalu data tersebut menjadi grafik gelombang yang dapat dibaca unsur kimianya dan dapat pula dilihat grafik deferensiasinya.

\section{Pengolahan Data}

\section{PCA (partial component analysis)}

Analisa data pencilan salah satunya menggunakan outlier removal partial component analysis, Data yang diambil adalah data yang berada didalam grafik dan menunjukan titik titik sampel biji kopi.

\section{Klasifikasi Biji Kopi}

Klasifikasi biji kopi dari 40 sampel yang berbeda jenis dan berbeda asal daerah yang sudah ditembakkan laser akan menghasilkan data prediksi yang akan dibangun dengan menggunakan metode PCA (partial component analysis). 


\section{Pre Treatment}

Setelah dilakukan membangunn model prediksi selanjutnya menghilangkan data pencilan dengan metode pretreatment Baseline Correction dengan bertujuan untuk menghilangkan noise yang ada dan memperbaiki hasil data yang didapat dari pembangunan model prediksi pada metode PCA (partial component analysis) dan bias mengurangi keakuratan data yang didapat.

\section{HASIL DAN PEMBAHASAN}

\section{Spektrum Deferensiasi Kopi}

Deteksi deferensiasi pada biji kopi menggunakan laser He-Ne pada frekuensi pulse $632 \pm 15 \mathrm{~Hz}$ dengan wavenumber $4000-10.000 \mathrm{~cm}^{-1}$ pada penelitian ini. Dari spectrum tersebut dapat kita lihat data keberadaan organic dan kandungan unsur kimia pada sampel kopi dengan bantuan laser He-Ne dengan beberapa sampel biji kopi yang terdiri dari kopi arabika dan kopi robusta. Berdasarkan spectrum raw ini, serapan yang mengindikasi adanya pengaruh antara laser He-Ne dengan berbagai zat organic, kandungan komposisi kimia yang dimana senyawa kimia yang terkandung pada biji kopi akan terlihat walaupun ada beberapa sampel dengan grafik yang sama akibat komposisi kimia pada suatu sampel sangat mendekati kesamaan, kita bisa melihat kadar atau komposisi kimia dengan cara membaca wavenumber yang tertera pada bagian bawah grafik.

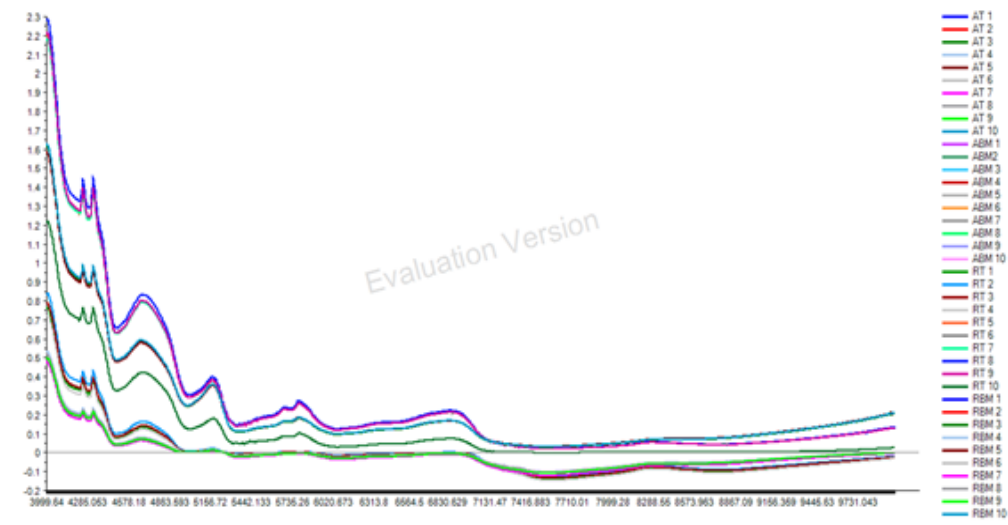

Gambar 1. Raw Spektrum LPAS Kopi

\section{Klasifikasi Deferensiasi Kopi (PCA)}

Setelah dilakukan akusisi spectrum pada biji kopi, langkah selanjutnya adalah mendeteksi keberadaan data pencilan dengan metode PCA yang. Analisa PCA berfungsi untuk mengetahui data pencilan yang dapat merusak data pendugaan pada deferensiasi spectrum. Setelah dilakukan analisa PCA untuk analisa senyawa kimia pada kopi factor yang akan menjelaskan total data sebesar 100\% dengan Factor-1 sebesar 98\%, dan Factor-2 sebesar 2\%. Hasil dari PCA dari jumlah 40 sampel kita hanya dapat melihat 14 sampel yang berupa titik biru, 26 titik lainnya telah tertutup oleh ke 14 titik tersebut dikarenakan beberapa sampel terdapat data yang sangat merip. Maka dengan itu kita memperoleh data kita melihat PC-1 98\% sementara PC-2 sebesar $2 \%$ hal ini bearti data yang diperoleh sangat akurat dengan total penjumlahan $100 \%$. Kemudian dilakukan metode koreksi baseline correction untuk mendapatkan data yang lebih baik. Sebelum itu kita akan melihat data RAW perbandingan arabika dan robusta dan perbandingan asal daerah penghasil kopi Bener meriah dan Takengon 


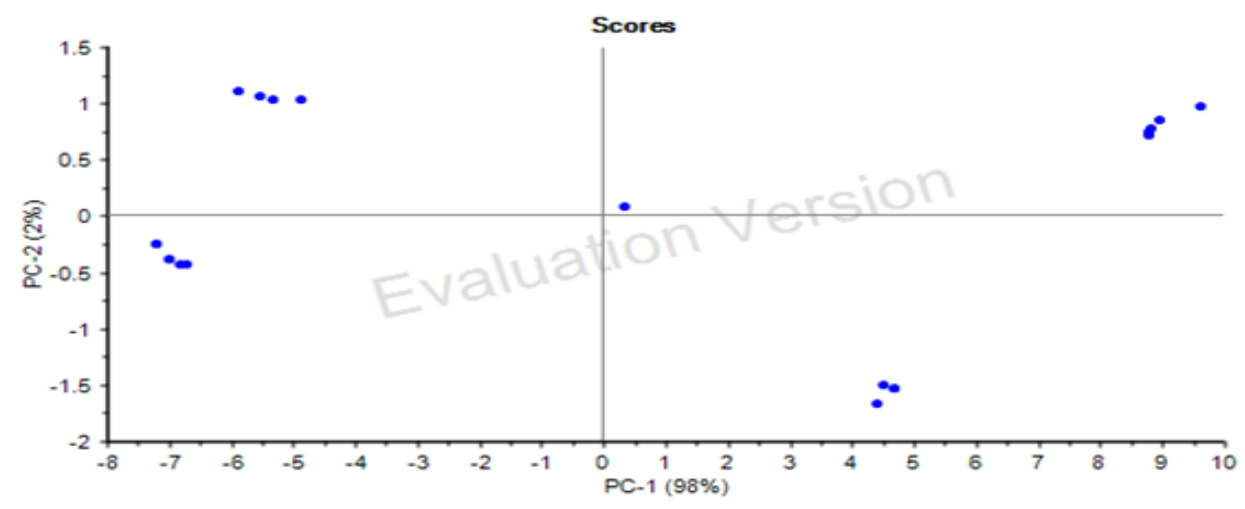

Gambar 2. Klasifikasi spectrum transmisi metode PCA

\section{Perbandingan Klasifikasi Berdasarkan Perbedaan Jenis Kopi}

Dengan melihat data pencilan dibawah kita melihat bahwa titik biru menunjukkan biji kopi arabika dan titik merah menunjukan biji kopi robusta, sekilas kita melihat bahwa titik biji kopi arabika dan titik biji kopi robusta terlihat menyatu dan saling menutupi satu sama lain. Artinya alat Laser photo acoustic ini belum mampu mendeteksi keberadaan biji kopi arabika dan mendeteksi biji kopi robusta sehingga titik titik tersebut saling menyatu dan saling menutupi, kemungkinan diakibatkan system pengaturan yang masih default untuk mempertajam sensor yang digunakan sehingga sensor yang digunakan lebih peka terhadap perbedaan biji kopi arabika dan biji kopi robusta.

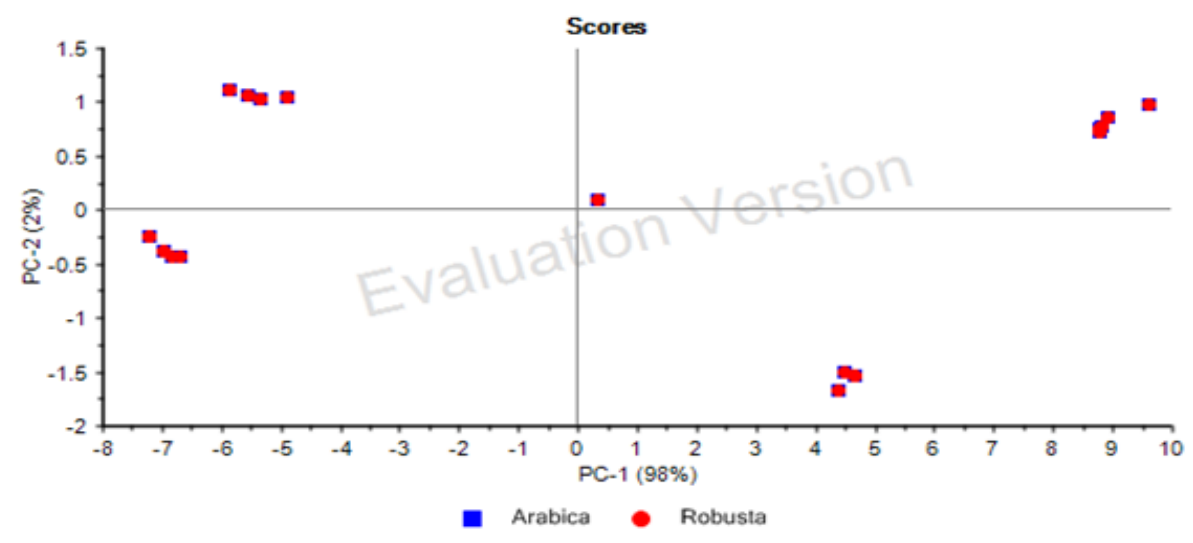

Gambar 3. Data Raw Perbandingan biji kopi arabika dan robusta.

\section{Perbandingan Klasifikasi Berdasarkan Perbedaan Daerah Penghasil Kopi}

Dengan melihat data dibawah maka dapat kita paparkan bahwa terpisahnya beberapa sampel yang dapat kita lihat dengan keterangan titik tersebut kita melihat titik berwarna biru dan biru muda itu adalah biji kopi yang berasal dari daerah Benermeriah dan titik berwarna hijau dan titik berwarna merah yaitu biji kopi yang berasal dari Takengon.

Kita bisa melihat bahwa pengelompokan yang terjadi adalah sampel biji kopi asal Bener meriah menyatu dengan sampel biji kopi dari Bener meriah juga walaupun berbeda jenis kopi arabika dan biji kopi robusta dengan keterangan biji kopi arabika Benermeriah titik berwarna biru dan biji kopi robusta Benermeriah titik berwarna biru muda. Begitu juga dengan sampel kopi asal Takengon, sampel sampel tersebut menyatu walaupun berbeda jenis kopi antara biji kopi arabika Takengon dan sampel biji kopi robusta asal Takengon dengan keterangan sampel 
biji kopi arabika asal Takengon berwarna merah dan sampel biji kopi robusta asal Takengon berwarna hijau.

Menurut pertinjauan saya, alat Laser photo acoustic mampu membedakan antara biji kopi yang berbeda daerah seperti sampel penelitian saya menggunakan sampel biji kopi asal Bener meriah dan sampel biji kopi asal Takengon terlihat sangay signifikan perbedaan antar sampel biji kopi tersebut, dengan sampel biji kopi yang berbeda daerah dengan begitu berbeda pula dengan ketinggian budidaya tanaman kopi tersebut berbeda ketinggian berbeda pula suhu alam dari kedua daerah tersebut, yang mana kita ketahui ketinggian daerah Bener meriah yaitu berkisar antara $2300 \mathrm{mdpl}$ sampai dengan $2500 \mathrm{mdpl}$ sedangkan daerah Takengon sendiri berkisar antara 1000 mdpl sampai dengan 1200 mdpl dan jika kita melihat suhu dari perbandingan antara kedua kota tersebut daerah Benermeriah memiliki suhu berkisar antara 15 derjat celcius sampai dengan 20 derajat celcius sedangkan daerah kota takengon sendiri berkisar antara 17 derajat celcius sampai dengan 23 derajat celcius.

Hal ini membuktikan bahwa perbedaan ketinggian daerah budidaya dan suhu rata rata daerah pembudidaya bias mengakibatkan perbedaan unsur dan komposisi kimia pada biji kopi arabika maupun arabika, hal ini telah dibuktikan oleh beberapa peneliti kopi diberbagai daerah, lintas nasional maupun peneliti internasional, dan hal yang perlu diketahui adalah alat Laser photo acoustic mampu membedakan biji kopi yang berbeda asal dan daerah yang ditempati dengan hanya menembakkan laser tanpa merusak bahan atau lebih dikenal dengan metode nondestructive.

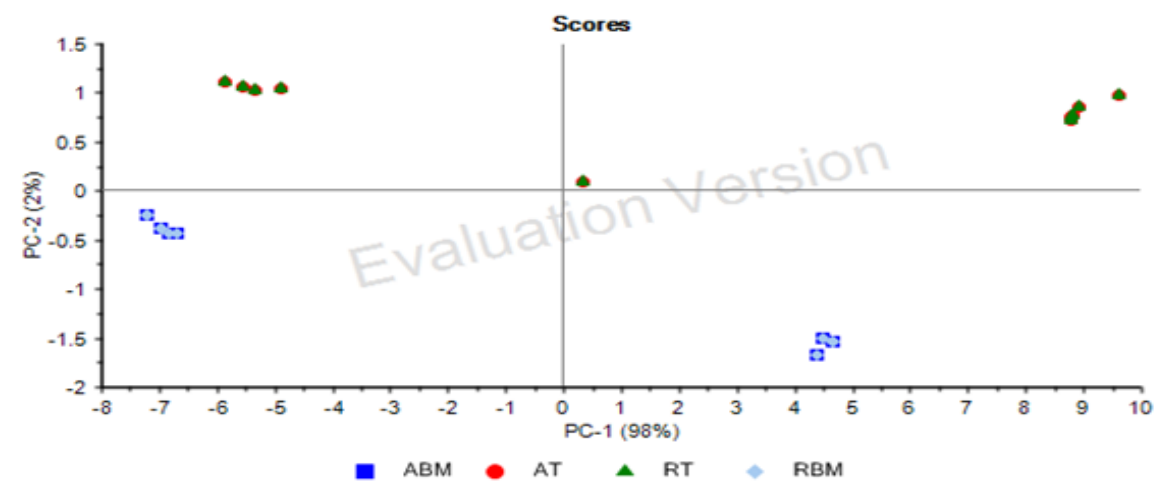

Gambar 4. Klasifikasi Data Raw Perbandingan asal daerah penghasil antara Benermeriah dan Takengon

\section{Rendemen}

Kemudian kita juga akan melihat loadings plot pada percobaan deferensiasi biji kopi ini pada gambar 5 :

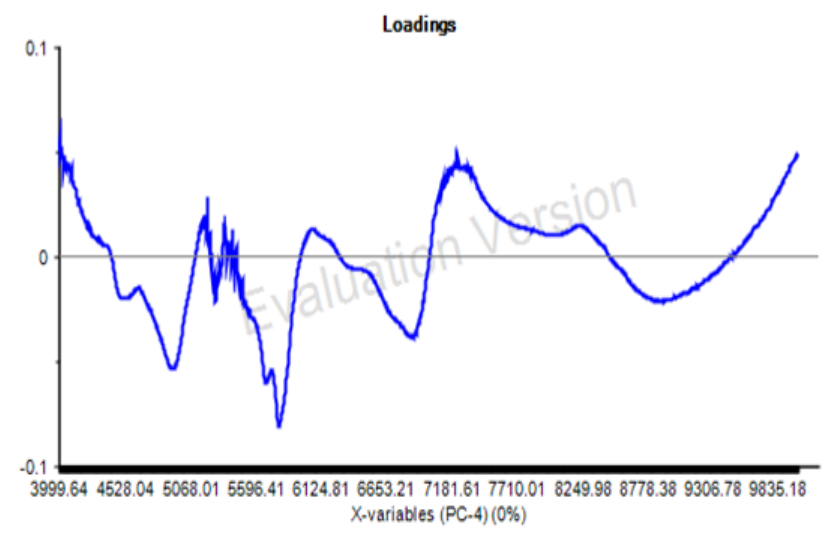

Gambar 5. Loading plot PCA 
Pada loading plot raw sampel biji kopi kali ini kita melihat dibeberapa titik terjadi noise, walaupun terjadi banyak noise tetapi tidak ada satupun noise yang besar, ini dikarenakan pada saat penelitian dan penembakan laser pada sampel benar benar focus dan hikmat, jika pada saat penembakan sinar laser terhadap sampel terjadi kilatan kilatan cahaya ataupun dengan suasana yang mengundang gelombang seperti gelombang cahaya, gelombang suara, gelombang elektromagnetik dan lain sebagainya akan sangat berpengaruh terhadap grafik loadings plot karena sensor mendeteksi gelombang gelombang sekitar sehingga jika itu terjadi maka akan terjadi noise yang besar dan data juga akan mengalami gangguan terhadap keakuratannya.

\section{Metode PCA Menggunakan Baseline Correction LPAS Biji Kopi}

Hasil dari pada koreksi spectrum menggunakan metode baseline correction diperoleh spectrum yang lebih baik hal ini terjadi karena data noise atau error pada spectrum raw telah dihilangkan. Hal yang membedakan antara spectrum baseline correction dan raw adalah kerapatan dan kerapian spectrum, semakin rapat dan rapi spectrum yang dihasilkan maka semakin baik hal itu dikarenakan dalam penentuan panjang relevan gelombang untuk mendeferensiasi biji kopi semakin mudah. Akan tetapi pada penelitian ini jika kita menggunakan Baseline correction akan menghilangkan beberapa data sehingga data yang awalnya sudah baik menjadi kurang baik tingkat keakuratannya, karena data yang sudah sangat baik ini harus dihilangkan beberapa noise sehingga menghilangkan data akurat yang dimilkinya.

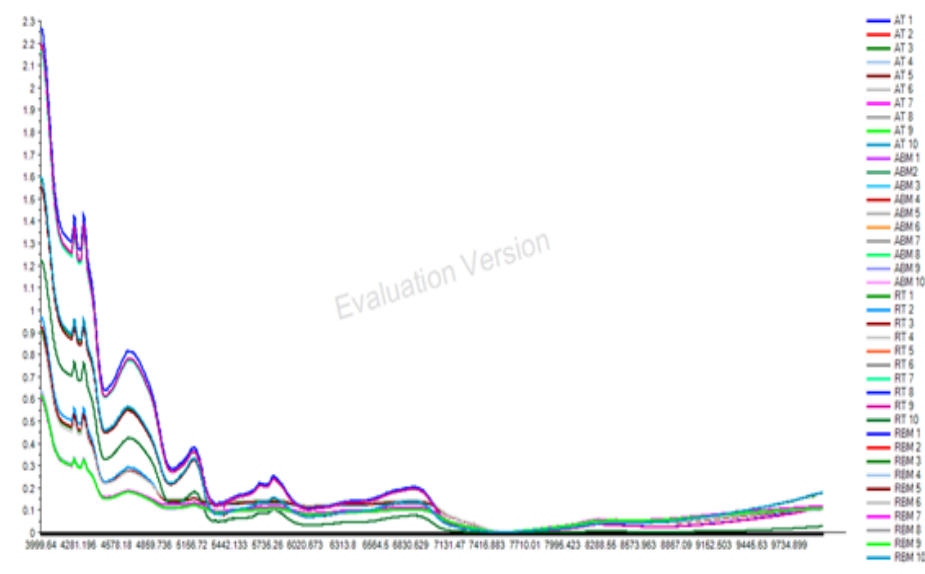

Gambar 6. Data PCA Menggunakan Pretreatment Baseline Correction

\section{Karatenoid}

Dengan melihat data ini kita menghitung jumlah titik biru yang berupa sampel biji

Kopi yang diteliti, total dari 40 titik sampel dan yang terdeteksi hanya 13 titik, berbeda pada data raw yang kita dapatkan dengan 40 jumlah sampel kita mendapati 14 sampel yang muncul didata pencilan, berkurang 1 sampel, seperti yang saya jelaskan diatas metode baseline ini mengurangi data agar terlihat sempurna dan menghilangkan beberapa noise, jika data yang sudah kita dapatkan itu baik dalam artian tanpa ada noise yang besar maka akan merusak data awal kita, untuk tingkat keakuratan data kita melihat pada gambar 13 disini PC-1 98\% sedangkan PC-2 yaitu 1\%, artinya ada kehilangan keakuratan data disini sehingga kita jumlahkan PC-1 dan PC-2 hanya mendapat 99\% berbeda jika kita melihat data raw diawal tanpa adanya metode baseline correction dengan PC-1 98\% dan PC-2 mendapat 2\%.

Oleh karena itu metode Baseline Correction kita butuhkan apabila data yang kita dapatkan memiliki noise yang banyak dan besar sehingga dapat disederhanakan oleh system 
dan membuat data yang sebelumnya memiliki niose yang besar menjadi data yang memiliki kerapatan spectrum sehingga memudahkan untuk membaca grafik spectrum yang telah diakusisi oleh alat Laser photo acoustic.

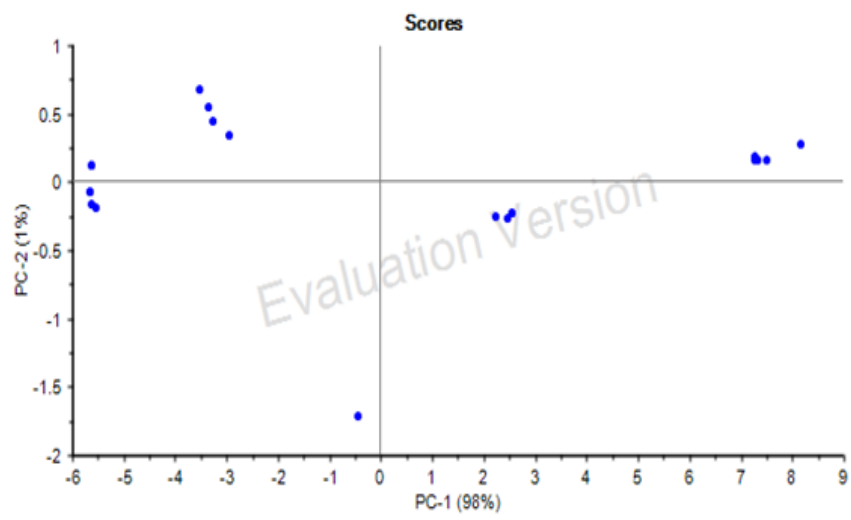

Gambar 7. Data Pencilan PCA yang sudah menggunakan pre treatment Baseline Correction

\section{Loading Plot menggunakan pre treatment}

Disini kita melihat bahwa loading plot yang telah menggunakan metode Baseline Correction menghilangkan hampir seluruh noise kecil yang ada, tetapi noise besar muncul begitu saja pada loading plot ini yang sebelumnya hanya ada noise kecil tanpa adanya noise yang besar sekarang dengan menggunakan metode baseline correction noise kecil menghilang dan membuat noise yang besar pada wave number 7181 sampai 7710 dan wave number 5068 sampai dengan wave number 5596, hal ini membuktikan bahwa tidak semua akan baik jika menggunakan metode baseline correction, gunakanlah metode ini jika benar benar membutuhkan atau memiliki data yang buruk. dapat dilihat pada Gambar 8 .

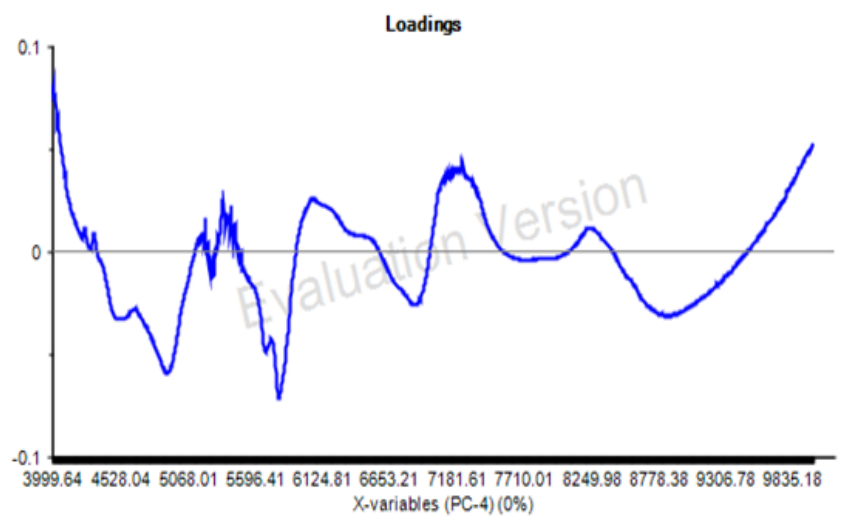

Gambar 8. Loading plot yang sudah menggunakan pretreatment Baseline Correction

\section{Data Perbandingan Perbedaan Daerah Metode PCA Menggunakan Pretreatment}

Kita melihat sangat jelas bahwa ada sesuatu yang salah pada data ini setelah menggunakan metode baseline correction, disini ada data sampel biji kopi yang melenceng dari tempat asalnya bahkan sangat jauh melenceng diakibatkan kehilangan data penting yang disederhanakan lewat metode baseline correction, dimana data sampel biji kopi arabika Takengon dan data sampel biji kopi robusta Takengon berada di tengah tengah lingkup atau kelompok sampel biji kopi arabika Bener meriah dan kelompok sampel biji kopi robusta 
Bener meriah yang ditandai oleh titik hijau berupa sampel biji kopi robusta Takengon dan titik merah berupa sampel biji kopi arabika Takengon.

Begitupun sebaliknya, kita melihat juga dari data ada yang sedikit melenceng setelah menggunakan metode baseline correction titik sampel biji kopi arabika Bener meriah dan titik sampel biji kopi robusta Bener meriah sedikit melewati garis grouping, walaupun sedikit ini sangat fatal dikarenakan penelitian ini untuk melihat deferensiasi total bukan untuk melihat deferensiasi satu atau dua senyawa kimia pilihan yang terkandung pada biji kopi, oleh karena itu menggunakan metode baseline correction pada penelitian ini dapat mengakibatkan beberapa sampel akan melenceng jauh dari keakuratan sehingga kita menggunakan data pencilan raw sebagai acuan untuk deferensiasi biji kopi ini.

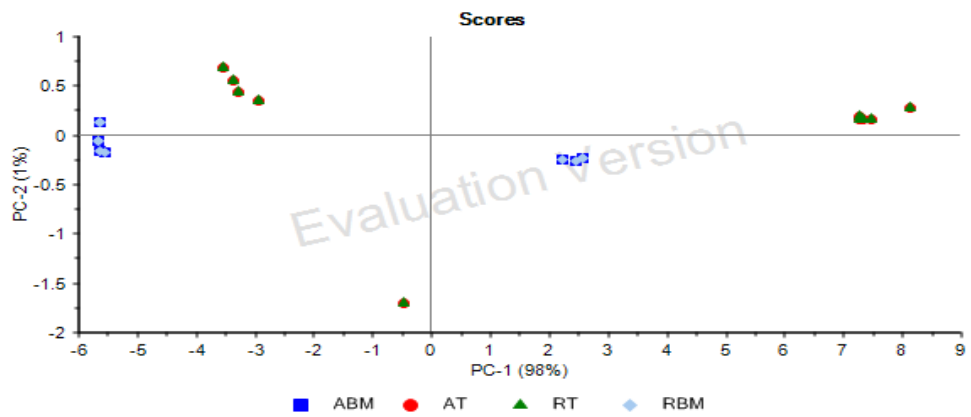

\section{PCA Menggunakan pretreatmen deferensiasi jenis kopi}

Didata ini kita melihat bahwa data PCA yang raw dan yang menggunakan metode Baseline Correction sama sama tidak dapat membedakan sampel biji kopi arabika dan sampel biji kopi robusta, maka dari itu pun alat Laser Photo Accoustic ini butuh pengembangan lebih lanjut agar dapat menyempurnakan beberapa penelitian yang belum dapat terdeteksi oleh alat ini, sehingga alat ini bisa berguna bagi bangsa dan Negara serta pengembangan ilmu lebih lanjut untuk saintis saintis muda syiah kuala.

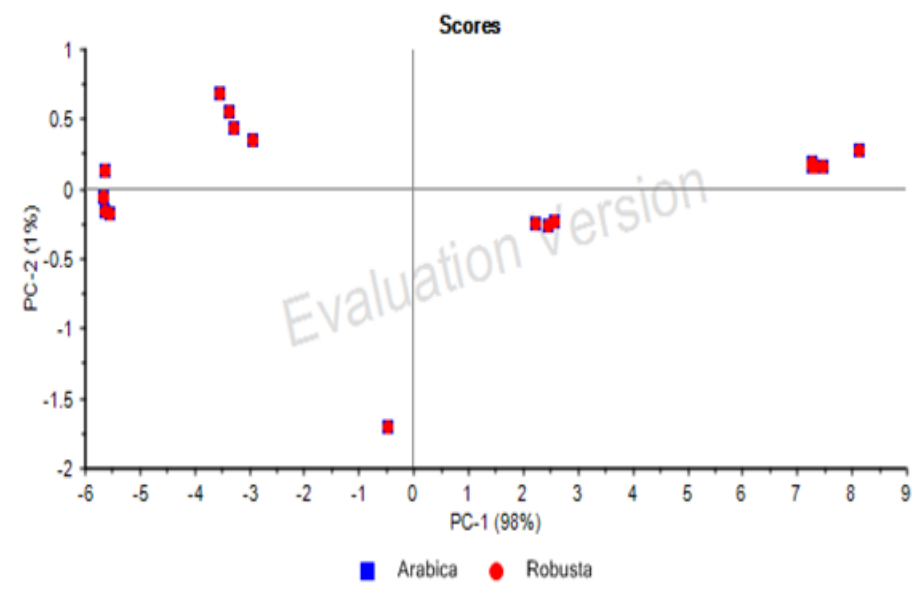

Gambar 10. Data PCA menggunakan Baseline Correction deferensiasi jenis kopi 


\section{KESIMPULAN DAN SARAN}

\section{Kesimpulan}

Aplikasi alat Laser Photo Accoustic dapat membedakan biji kopi berdasarkan asal atau daerah tempat budidaya yang didalam penelitian ini menggunakan biji kopi arabika dan biji kopi robusta dengan asal daerah Benermeriah dan asal daerah Takengon masing masing berjumlah 40 sampel.Aplikasi alat Laser Photo Accoustic ini belum mampu sepenuhnya membedakan yang mana biji kopi berdasarkan jenisnya didalam penelitian ini menggunakan biji kopi arabika dan biji kopi robusta.Data pencilan dari PCA raw mendapat 14 titik dari 40 sampel dan memiliki PC-1 98\% dan PC-2 2\% sehingga dengan penjumlahan mendapat hasil 100\% kemudian data pencilan yang telah menggunakan Baseline Correction mendapat 13 titik dari 40 sampel den memiliki PC1 sebesar 98\% dan PC-2 sebesar 1\% jika dijumlahkan mendapat keakuratan 99\%.Data loading plot membuktikan bahwa loading plot yang menggunakan metode baseline correction akan menghilangkan noise kecil dan menimbulkan noise yang besar pada penelitian ini. Berdasarkan evaluasi nilai bahwa menggunakan metode baseline correction pada penelitian ini akan merusak data sehingga menjadikan beberapa data sampel menjadi error.

\section{Saran}

Adapun dari penelitian ini dapat diberikan saran alat Laser photo accoustik harus dikembangkan lebih lanjut khususnya dalam bidang deferensiasi biji kopi berdasarkan jenis kopi dan untuk peneliti setelah ini untuk memodifikasi set system kepekaan terhadap gelombang agar bisa melalukan penelitian perbandingan biji kopi arabika dan biji kopi robusta untuk kedepannya. 


\section{DAFTAR PUSTAKA}

Edy Pangabean 2011. Buku Pintar Kopi $1^{\text {st }}$. Agromedia Pustaka: Jakarta.

Sofyana Nadya, 2011. Fakta Tentang Kopi. Cahaya Atma Pustaka: Yogyakarta.

Young, H. D. 2003. Fisika Universitas J1 2/10. Erlangga. Jakarta.

Yuniyati, N dan Soleh E, Dedi. 2014. Varietas Unggul Kopi Arabika Gayo 1 dan Gayo Pusat Penelitian dan Perkembangan Perkebunan. Bogor. 